Short Communication

\title{
A COM PARATIVE STUDY ON COPING STRATEGIES AND SENSE OF COHERENCE AMONG CAREGIVERS OF MENTALY AND NEUROLOGICALLY ILL PATIENTS IN KASTURBA HOSPITAL, MANIPAL, KARNATAKA.
}

\author{
Rigi George' ${ }^{1}$, Asha Nayak ${ }^{2} \&$ Anjalin D'Souza ${ }^{3}$ \\ ${ }^{1}$ M .Sc. (N) Student-2010-12 batch, ${ }^{2}$ Assistant Professor, Department of Psychiatric/M ental Health Nursing, \\ ${ }^{3}$ Assistant Professor, Department of Childl Health Nursing, Manipal College of Nursing Manipal, \\ Manipal University, Manipal, Udupi, Karnataka - 576104 \\ Correspondence: \\ Asha Nayak \\ Assistant Professor, Department of Psychiatric/M ental Health Nursing, Manipal College of Nursing Manipal, \\ Manipal University, Manipal, Udupi, Karnataka - 576104 \\ Mobile : +919448252940 E-mail : ashanarasimha@yahoo.co.in
}

\section{Abstract:}

Introduction : Diseases take a toll not only on those affected, but also on the ones around them. Regardless of language, culture or country caregiving has become an everyday part of life for millions of people around the globe. Though differently named on each continent, these millions of 'carers' or 'caregivers' provide care to family members, partners or friends each year because they are sick, elderly or have a disability. This cross-sectional study was undertaken to assess the coping strategies and sense of coherence among caregivers of patients with mental and neurologic illness.

Methods : Comparative, descriptive study design was used. The study was conducted among 40 caregivers of clients who were admitted in psychiatric and neurologic wards of Kasturba Hospital, M anipal. Tools used were demographic proforma, coping scale and sense of coherence-29 scale.

Results : Findings showed that there was no significant difference in the coping strategies and sense of coherence of caregivers of mentally and neurologically ill patients $(p>0.05)$. The study also revealed that there was no association between sense of coherence and coping strategies of caregivers of mentally ill patients $(p=1)$.

Conclusion : Both the caregivers of mentally and neurologically ill patients used almost same coping strategies such as substance abuse and denial. Both the caregivers of mentally and neurologically ill patients considered caring their relative during illness is meaningful. The study highlights the need for family interventional programs to address the specific concern, related to coping and sense of coherence of caregivers.

Keywords: Caregivers, Coping, Sense of Coherence, M entally and Neurologically ill patients.

\section{Introduction: objectives, purpose to be mentioned}

Diseases take a toll not only on those affected, but also on the ones around them ${ }^{1}$. Regardless of language, culture or country caregiving has become an everyday part of life for millions of people around

Access this article online Quick Response Code

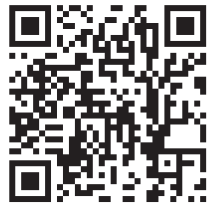

the globe. Though differently named on each continent, these millions of 'carers' or 'caregivers' provide care to family members, partners or friends each year because they are sick, elderly or have a disability. The care they provide is unpaid or often unrecongnized and undersupported. In most countries, family care is the primary means of caregiving with immediate or extended family rather than institutions ${ }^{2}$. The objectives of the study is to assess the sense of coherence and coping strategies of caregivers of clients with mentally ill and neurologically ill and to compare the coping strategies and sense of coherence of caregivers of mentally and neurologically ill patients

\section{Materials and methods:}

After obtaining the administrative permission from the 
authority ethical clearance was obtained. Consent was taken from participants of the study

Fourty caregivers of patients diagnosed as paranoid schizophrenia, severe depression with or without psychotic symptoms, recurrent depressive disorder, dysthymia, psychosis and bipolar affective disorder according to ICD 10 criteria were selected from psychiatric ward and fourty caregivers of patients diagnosed as stoke were selected from neurologic wards of $\mathrm{KH}, \mathrm{M}$ anipal. Caregivers were above 20 years, living with the patient for atleast one year and taking care of the patients at home and hospital was included in the study. Caregivers having chronic physical illness, past/current psychiatric illness, unwilling to participate in the study and those who were illiterate were excluded from the study.

\section{Results:}

Coping Scale is a self reported rating scale comprised of twenty six questions. The maximum score was 130 and minimum score was 26. Based on the total scores obtained, the subjects were classified into three categories- Low coping: 26-60, moderate coping: 61-95, High coping: 96130.

Sense Of Coherence Scale is a standardized to ol of 29 items which is scored in a seven point rating scale. The maximum score was 203 and minimum score was 29. The language validity was determined by giving the translated Kannada and Malayalam version of tools to language experts and translated back to English.. Descriptive statistics (mean, mean percentage, Standard deviation ) and inferential statistics (Independent sample t-test, chi-square) were used for the analysis.

\section{Tables}

Table 1: Frequency and percentage distribution of sample characteristics of caregivers of mentally and neurologically ill patients

$n=40+40=80$

\begin{tabular}{lcccc}
\hline Sample characteristics & \multicolumn{2}{c}{$\begin{array}{c}\text { Caregivers of } \\
\text { mentally ill } \\
\text { patients }\end{array}$} & \multicolumn{2}{c}{$\begin{array}{c}\text { Caregivers of } \\
\text { neurologically } \\
\text { ill patients }\end{array}$} \\
& $\mathrm{f}$ & $\%$ & $\mathrm{f}$ & $\%$ \\
\hline Age in years & 11 & 27.5 & 13 & 32 \\
$20-30$ & 11 & 27.5 & 11 & 27.5 \\
$31-40$ & 7 & 17.5 & 9 & 22.5 \\
$41-50$ & 8 & 20 & 4 & 10 \\
$51-60$ & 3 & 7.5 & 3 & 7.5 \\
61 and above & & & & \\
Gender & 22 & 55 & 21 & 52.5 \\
Male & 18 & 45 & 19 & 47.5 \\
Female & & & & \\
& & & & \\
Marital status & 28 & 70 & 27 & 67.5 \\
Married & 9 & 22.5 & 12 & 30 \\
Single & 1 & 2.5 & 0 & 0 \\
Divorced & 2 & 5 & 1 & 2.5 \\
Widowed & & & & \\
& & & & \\
Religion & 38 & 95 & 38 & 95 \\
Hindu & 1 & 2.5 & 0 & 0 \\
Christian & 1 & 2.5 & 2 & 5 \\
Muslim & & & &
\end{tabular}




\begin{tabular}{|c|c|c|c|c|}
\hline \multirow[t]{2}{*}{ Sample characteristics } & \multicolumn{2}{|c|}{$\begin{array}{c}\text { Caregivers of } \\
\text { mentally ill } \\
\text { patients }\end{array}$} & \multicolumn{2}{|c|}{$\begin{array}{c}\text { Caregivers of } \\
\text { neurologically } \\
\text { ill patients }\end{array}$} \\
\hline & $f$ & $\%$ & $f$ & $\%$ \\
\hline \multicolumn{5}{|l|}{ Educational level } \\
\hline Illiterate & 1 & 2.5 & 0 & 0 \\
\hline Primary & 2 & 5 & 2 & 5 \\
\hline Middle school & 8 & 20 & 5 & 12.5 \\
\hline High school & 14 & 35 & 17 & 42.5 \\
\hline Secondary school & 6 & 15 & 5 & 12.5 \\
\hline Diploma & 9 & 22.5 & 9 & 22.5 \\
\hline Graduate & 0 & 0 & 2 & 9 \\
\hline \multicolumn{5}{|l|}{ Occupation } \\
\hline Unemployed & 15 & 37 & 13 & 32.5 \\
\hline Unskilled worker & 17 & 42.5 & 13 & 32.5 \\
\hline Office worker & 7 & 17.5 & 8 & 20 \\
\hline Professional & 1 & 2.5 & 6 & 15 \\
\hline
\end{tabular}

Monthly family income in Rs.

$<2000$

2000- 5000

5001- 8000

$8001-11,000$

11,000

Relationship with the client

Parents

Son/Daughter

Siblings

Spouse

Others

\section{Type of family}

Joint

Nuclear

Extended

\section{Place of living}

Urban

Rural
33

14

4

9

7

6

28

12

0

7
35

10

22.5

17.5

15

70

30

0

24

60

37.5

2.5

12.5

47.5

12.5

22.5

30

7.5

3$$
7.5
$$$$
5
$$

70

30

0


Table 2: Frequency and percentage distribution of sample characteristics of mentally and neurologically ill patients

\begin{tabular}{|c|c|c|c|c|}
\hline \multirow[t]{2}{*}{ Sample characteristics } & \multicolumn{2}{|c|}{$\begin{array}{l}\text { Mentally ill } \\
\text { patients }\end{array}$} & \multicolumn{2}{|c|}{$\begin{array}{l}\text { Neurologically } \\
\text { ill patients }\end{array}$} \\
\hline & f & $\%$ & $f$ & $\%$ \\
\hline \multicolumn{5}{|l|}{ Age in years } \\
\hline $20-30$ & 14 & 35 & 4 & 10 \\
\hline $31-40$ & 9 & 22.5 & 3 & 7.5 \\
\hline $41-50$ & 3 & 7.5 & 9 & 22.5 \\
\hline $51-60$ & 8 & 20 & 13 & 32.5 \\
\hline 61 and above & 6 & 15 & 11 & 27.5 \\
\hline \multicolumn{5}{|c|}{ Duration of illness in years } \\
\hline Less than 2 & 20 & 50 & 21 & 52.5 \\
\hline$\geq 2-5$ & 20 & 50 & 19 & 47.5 \\
\hline \multicolumn{5}{|c|}{ Duration of present hospitalization in weeks } \\
\hline Less than 2 & 33 & 82.5 & 33 & 82.5 \\
\hline$\geq 2-4$ & 7 & 17.5 & 7 & 17.5 \\
\hline \multicolumn{5}{|c|}{ Number of hospitalizations } \\
\hline One & 11 & 27.5 & 15 & 37.5 \\
\hline Two & 12 & 30 & 12 & 30 \\
\hline Three & 9 & 22.5 & 6 & 15 \\
\hline More than three & 8 & 20 & 7 & 17.5 \\
\hline
\end{tabular}

Table 3: Mean percentage and standard deviation of domains of coping strategies among caregivers of mentally and neurologically ill patients

\begin{tabular}{lcccccc}
\hline Domains & $\begin{array}{c}\text { No.of } \\
\text { Items }\end{array}$ & $\begin{array}{c}\text { Maximum } \\
\text { possible } \\
\text { score }\end{array}$ & $\begin{array}{c}\text { Caregivers of } \\
\text { mentally ill } \\
\text { patients }\end{array}$ & $\begin{array}{c}\text { Caregivers of } \\
\text { neurologically } \\
\text { ill patients }\end{array}$ \\
\hline Active coping & 3 & 15 & 10.47 & 3.02 & 10.47 & 3.02 \\
Venting & 3 & 15 & 9.20 & 2.37 & 9.67 & 2.30 \\
Self distraction & 3 & 15 & 9.45 & 3.54 & 8.77 & 2.36 \\
Denial & 3 & 15 & 10.95 & 2.55 & 10.57 & 2.44 \\
Emotional support & 3 & 15 & 9.07 & 3.53 & 8.90 & 2.79 \\
Substance abuse & 2 & 10 & 17.85 & 4.20 & 17.25 & 3.94 \\
Spiritual support & 2 & 10 & 6.97 & 2.45 & 6.77 & 2.22 \\
Planning & 2 & 10 & 6.55 & 2.87 & 6.52 & 2.45 \\
Positive reframing & 3 & 15 & 9.85 & 2.90 & 9.50 & 2.39 \\
Self blame & 2 & 10 & 6.57 & 2.25 & 6.67 & 1.52 \\
\hline Total & & & & 96.93 & & 95.07 \\
\hline
\end{tabular}


Table 4: Mean percentage and standard deviation of domains of sense of coherence among caregivers of mentally ill and neurologic patients

\begin{tabular}{lcccccc}
\hline Domains & $\begin{array}{c}\text { No.of } \\
\text { Items }\end{array}$ & $\begin{array}{c}\text { Maximum } \\
\text { possible } \\
\text { score }\end{array}$ & \multicolumn{2}{c}{$\begin{array}{c}\text { Caregivers of } \\
\text { mentally ill } \\
\text { patients }\end{array}$} & $\begin{array}{c}\text { Caregivers of } \\
\text { neurologically } \\
\text { ill patients }\end{array}$ \\
\hline Comprehensibility & 11 & 77 & 57.23 & 12.88 & 58.44 & 12.43 \\
Manageability & 10 & 70 & 63.07 & 12.46 & 67.60 & 10.97 \\
Meaningfulness & 8 & 56 & 65.80 & 9.46 & 70.21 & 10.08 \\
\hline Total & & & & 96.93 & & 95.07 \\
\hline
\end{tabular}

Table 5: Comparison of coping and sense of coherence between caregivers of mentally and neurologically ill patients

\begin{tabular}{lccc} 
& & & \multicolumn{2}{c}{$n=40+40=80$} \\
\hline Variables & df & 't' value & 'p' value \\
\hline Coping & 78 & 0.392 & 0.696 \\
Sense of coherence & 78 & 1.005 & 0.318 \\
\hline *significant at $p<0.05$ level & &
\end{tabular}

\section{Discussion :}

The present study findings are supported by the previous study conducted by Eaton (2011) to examine the coping strategies of family members of hospitalized psychiatric patients showed that the common coping strategies used by family members were substance abuse, avoidance, and spirituality ${ }^{5}$.

Binil V (2008) conducted a correlative study to assess burden and coping strategies among the caregivers of patients with affective disorders in Kasturba Hospital and A.V Baliga Hospital, Karnataka which contradicts the findings of the present study. Out of 100 caregivers, $32 \%$ of caregivers were found to be using medium coping and $68 \%$ were using high coping. Mean percentage score was highest ie $86 \%$ in the area of planning. Lowest mean percentage score ie $34 \%$ was in humour, substance use and behavioural disengagement ${ }^{6}$.

Nilsson , Axelsson ,Gustafson, Lundman , Norberg (2001) conducted a study on well-being, sense of coherence, and burnout in stroke victims and spouses during the first few months after stroke in Sweden which contradicts the findings of the present study. Findings showed that the scores of the components composing the Sense of Coherence showed that four stroke victims and one spouse appeared to be low concerning meaningfulness, which probably makes coping with hardship still harder. Findings suggested that individuals with low Sense of Coherence scores had certain difficulties in coping with their situation?

Now a days, the treatment is pointed out not only to the client, but the whole family. Sense of Coherence scale can be used as a baseline measurement for detecting the diseases or illness which may threaten the individual. So the nurses can use this tool as a daily basis both in the hospital and in the community settings.

Nurses who are caring for mentally ill and stroke clients to be sensitive to family caregivers needs and should give timely advice to the caregivers. The concepts of caregiving and effects of long term illness to the family members should incorporate into the nursing curriculum. Hence it helps the students to administer self reported questionnaires to the client and family and to identify them very earlier and to sensitize future professionals in this area.

The nurse administrators of mental health services should be aware of the needs of the carers of patients having long term illness and formulate policies which enforces mental 
health professionals to include psychosocial interventions in their day to-day interventional activities with the patients and caregivers, both in hospital and in the community settings. They can also include coping scale and Sense of Coherence scale mandatory for client assessment, so the client has a better prognosis in terms of holistic care.

Nurses can expand the studies in the area of sense of coherence and see how it can be used in better quality care of the client and helpful for the early identification of illness.

\section{References:}

1. Emotional support is the most important form of care [Internet]. Times Of India. 2011 Jul 24. Available from:http://articles. timesofindia.indiatimes.com > Collections.

2. Caring for the caregiver: Why your mental health matters when you care for others. World Federation For M ental Health. [Internet]. 2010 [updated Oct 18; cited Nov 10].Retreived from url:http:// www.wfmh.org.

3. Creado DA, Parkar SR, Kamath RM .Burden and coping of caregivers in relation to the level of functioning in patients with chronic schizophrenia. IndianJ Psychiatry.2006Jan;48(1):27-33.

4. Van M, Hinojosa MS, Rittman M R. Influence of sense of coherence on caregiver burden and depressive symptoms at 12 months poststroke,2008 May-Jun;15(3):272-82. Available from: http:// web.ebscohost.com/ehost/pdfviewer/pdfviewer?vid =15\&hid=112 \&sid=ffc8d14b-e981-40dd-8762-6f958ffe0172\%

5. Eaton PM, Davis BL, Hammond PV, Condon EH, McGee ZT. Coping Strategies of Family Members of Hospitalized Psychiatric Patients. Nursing Res and Pract. 2011 .Available from: www.hindawi.com/ journals/nrp/2011/392705/

6. Binil V .A correlative study of burden and coping strategies among the caregivers of patients with affective disorders in selected hospitals of Udupi district, Karnataka.[M .Sc thesis].August 2008.M anipal:M anipal University.

7. Nilsson I, Axelsson K, Gustafson Y, Lundman B, Norberg A. Well-being, sense of coherence, and burnout in stroke victims and spouses during the first few months after stroke.[Internet].Scand J Caring Sci.[updated 2001; cited 2002]Available from:http:// web.ebscohost.com.sweden

\section{Conclusion :}

In summary, the present study has shown that there was no significant difference between sense of coherence and coping experienced by caregivers of patients with mental and neurological illness. Future studies can be replicated by random sampling method, on different groups of mentally ill patients and longitudinal studies can also be conducted to find out the pattern of coping and sense of coherence over time.

We acknowledge all the subjects who participated in the study willingly. 